Finding Character Strengths Through Loss: An Extension of Peterson and Seligman (2003)

\author{
Stephen M. Schueller ${ }^{1}$, \\ Eranda Jayawickreme ${ }^{2}$, \\ Laura E. R. Blackie ${ }^{2}$, \\ Marie J. C. Forgeard ${ }^{3}$, \\ Ann Marie Roepke ${ }^{3}$ \\ ${ }^{1}$ Northwestern University, \\ ${ }^{2}$ Wake Forest University, \\ ${ }^{3}$ University of Pennsylvania
}

Accepted for publication in Journal of Positive Psychology. Published by Taylor \& Francis. This article may not exactly replicate the final version published in the Taylor \& Francis journal. A link to the published article: http://dx.doi.org/10.1080/17439760.2014.920405 


\begin{abstract}
People can experience positive changes even in the midst of adversity and loss. We investigated character strengths following three recent shooting tragedies in the United States. Drawing from an Internet database of respondents to the Values in Action Inventory of Strengths (VIA-IS), we compared responses from three groups of participants $(N=31,429)$ within close proximity of each event: those who completed it eight months prior to the event, and one month and two months after. Results suggested that for one of the events, participants who completed the VIAIS after the event showed slightly different levels of self-reported character strengths compared to participants who completed the VIA-IS before the event, with some mean levels higher and others lower. The observed differences in character strengths were inconsistent across follow-up periods, and effect sizes were small (Cohen's $d$ values from -.13 to .15). These findings raise questions about whether and how tragedies might catalyze differences in character strengths.
\end{abstract}

Keywords: Character strengths, posttraumatic growth, growth, VIA-IS, development, traumatic events 


\section{Finding Character Strengths Through Loss: \\ An Extension of Peterson and Seligman (2003)}

In recent years, considerable research has documented the transformative power that experiences of adversity can have in re-shaping an individual's character and priorities in life (Tedeschi \& Calhoun, 2004). Peterson and Seligman (2003) demonstrated that significant differences in self-reported character strengths such as love, gratitude, and kindness followed the

September $11^{\text {th }} 2001$ terrorist attacks. However given that their study design that made use of measures continuously collected on an Internet website, they could not demonstrate causality. In this article, we pay both our respects to Chris Peterson as a mentor and friend, and extend his findings by examining whether such changes in self-reported strengths can be observed in three recent shooting tragedies in the United States: Virginia Polytechnic Institute and State University (2007), a movie theater in Aurora, Colorado (2012), and Sandy Hook Elementary School in Newtown, Connecticut (2012).

\section{Chris Peterson, Director of Virtue}

The field of positive psychology recently experienced a loss in the passing of one of our great luminaries, Dr. Christopher Peterson. Chris was an inspiration, a mentor, a colleague, and a friend to all of the authors on this paper. We could share many stories about the time we spent with Chris, and each of these stories would reflect the value he placed on connecting with people, listening to their stories, learning from their experiences, and remaining fully present during all his interactions. He was someone who took pleasure in his relationships, and was always happy to give his time in the service of others. During the first and second authors' time at the University of Pennsylvania during graduate school, Chris would frequently visit their office to talk about how they were handling the challenges of graduate school, offer his advice 
on how to further their training in positive psychology, or just joke to the first author about the dangers of being left-handed! Chris was not only a great scholar, but also a kind and caring man who enacted the values and character strengths that he researched.

Chris' research legacy matched his personality: large, creative, and transformational. Chris was an expert on how people capitalize on their personal strengths and his work on character strengths was foundational for positive psychology. In this paper, we extend Chris' legacy by using his measure, method, and argument to conduct further research on the extent to which experiences of tragedy can shape an individual's character. Through doing so, we test the assumption that adversity can provide a unique opportunity for the development of important character strengths by replicating and extending Chris' prior work on changes in character strengths following tragedies (Peterson \& Seligman, 2003).

\section{Posttraumatic Growth - Character Development in the Aftermath of Adversity}

The Nature of Posttraumatic Growth. In the aftermath of adversity, most individuals try to accept the harm caused by the stressor(s), find meaning in their experience, and, in some instances, may achieve personal growth (Schwarzer \& Knoll, 2003). The construct of posttraumatic growth (PTG) refers to the degree to which an individual believes he or she has grown and developed as a person as a result of struggling with trauma or crisis (Tedeschi \& Calhoun, 2004). Psychologists have also referred to such changes as stress-related growth or benefit finding, among other terms (Helgeson, Reynolds, \& Tomich, 2006). Although various changes may occur following adverse circumstances, the most commonly reported positive changes include improved relations with other people, the identification of new possibilities for one's life, increased personal strength, positive spiritual change, and enhanced appreciation of life (Tedeschi \& Calhoun, 1996). Additionally, Joseph and Linley’s (2008) organismic valuing 
theory posits changes in an individual's personality and social relationships (specifically in domains of personal growth, purpose, self-acceptance, environmental mastery, autonomy and relationships), but proposes that these changes can only occur in supportive social environments in which the individual feels autonomous, competent, and connected to other people.

PTG differs from resilience in the following ways:

The individual has not only survived, but has experienced changes that are viewed as important, and that go beyond what was the previous status quo. PTG is not simply a return to baseline - it is an experience of improvement that for some persons is deeply profound. (Tedeschi \& Calhoun, 2004, p. 4)

The changes noted above are conceptually related to the development of important qualities of character, such as diligence, generosity, love, and purpose (Peterson \& Seligman, 2004). Recent research has demonstrated that a wide range of events - including cancer, sexual assault, natural disasters, and HIV/AIDS — can lead to the positive change characteristic of PTG (Lindstrom, Cann, Calhoun, \& Tedeschi, 2011).

Mechanisms of PTG. How does PTG happen? Researchers have turned their attention to a variety of possible mechanisms of growth (e.g., Janoff-Bulman, 1989; 2004; Joseph, Murphy, \& Regel, 2012; Park, Aldwin, Fenster, \& Snyder, 2008). Several different theories suggest that PTG arises through cognitive processing: Adversity can challenge people's assumptions about themselves and the world, leading to changed schemas regarding their personal safety and the benevolence of the world, among other things (Janoff-Bulman, 1989). In particular, trauma can act as an "earthquake" that shatters people's assumptive worlds and thus prompts them to rebuild new, more sophisticated belief systems that are more resistant to future threat (Tedeschi \& Calhoun, 2004). Cognitive processing of the event aids the disengagement 
from these shattered assumptions and may eventually lead to posttraumatic growth. Tedeschi and Calhoun (2004) claim that cognitive processing of the event is accompanied by high levels of distress, at least initially; shattered assumptions are characterized by intrusive thoughts, memories, and counter-factual thinking about how the incident could have been avoided. However, when individuals move past these intrusive thoughts and comes to terms with the event, they may find themselves in a position to experience some of the positive life changes outlined earlier (cf. Tedeschi \& Calhoun, 2004). Some theorists have even posited that people may be intrinsically motivated to cognitively accommodate negative experiences in order to grow (Joseph \& Linley, 2005), and the processes of self-disclosure, deliberate rumination, and social support may help people to cognitively process trauma in adaptive ways (Prati \& Pietrantoni, 2009; Taku, Cann, Tedeschi, \& Calhoun, 2009; Tedeschi \& Calhoun, 2004). Tedeschi \& Calhoun (2004) note that this reflection and subsequent reconfiguration of assumptions about the world may result in the development of character strengths, such as those associated with wisdom and temperance.

Measurement of PTG. One controversy in PTG research involves methodological challenges in separating quantifiable change in personality over time from retrospective beliefs about possible changes in personality, which may function as coping strategies or as cognitive distortions (Frazier \& Kaler, 2006). For example, it is possible that the positive changes people report simply reflect their attempts to cope with the situation by restoring a sense of self-esteem, control, and optimism (Taylor, 1983). Indeed, adjusting desires and expectations to cope with adverse situations can be seen as an adaptive exploration of the positive aspects present in any situation. It is unclear from the existing evidence whether the positive changes individuals report following adversity are actually associated with concurrent positive changes in beliefs and 
behaviors, due to the over-reliance on retrospective measurement, self-report methods, and crosssectional studies.

Prospective, longitudinal studies are needed to reliably track change over time. It is difficult to design such studies, however, because for most trauma victims, it is not possible to predict when tragedy will strike. Peterson and Seligman (2003) however had a unique opportunity to compare measures collected before and after a tragedy: the 9/11 terrorist attacks on the World Trade Center in New York City. Using a dataset of continuously collected selfreports of character strengths allowed them to bypass some of the measurement limitations of past research and empirically assess whether the experience of adversity is associated with differences in virtues and character strengths over time. Although this study did not employ a prospective longitudinal design, its authors were able to make group comparisons, testing differences in character strengths between the following two groups: individuals who completed relevant measures before each tragedy, and other individuals who completed the measures afterward. The dataset consisted of responses to the Values in Action Inventory of Strengths questionnaire (VIA-IS) that measures 24 character strengths organized under six core virtues: wisdom, courage, humanity, justice, temperance, and transcendence. In comparing participants' responses to the VIA-IS two months prior to 9/11 and two months afterwards, Peterson and Seligman (2003) found significant differences in the following strengths: gratitude, hope, kindness, leadership, love, and spirituality, and teamwork. Given that this study was observational in nature, and did not track the same individuals over time, one cannot conclude that this event caused changes in strengths. However, the results are consistent with the notion of PTG and suggest that adversity can provide opportunities for the nourishment of important virtues and character strengths. 
In further work, Peterson, Park, Pole, D’Andrea and Seligman (2008) examined the relationship between retrospective reports of PTG and the development of character strengths more explicitly. They assessed the relationship between the Posttraumatic Growth Inventory (PTGI; Tedeschi \& Calhoun, 1996) and the VIA-IS (Peterson \& Seligman, 2004). All character strengths were positively and significantly associated with PTG, with higher correlations for strengths more theoretically relevant to PTG (e.g. love, religiosity). These preliminary data provided evidence that PTG may reflect significant changes in the character of an individual.

The present study builds on Peterson's findings (Peterson \& Seligman, 2003; Peterson et al., 2008) by examining levels of self-reported character strengths in individuals in the surrounding areas before and after three recent shooting tragedies in the United States: Virginia Tech (2007), a movie theater in Aurora, Colorado (2012), and Sandy Hook Elementary School in Newtown, Connecticut (2012). In light of prior research, we expect that, in spite of the negative effects caused by tragedy, these events may function as a catalyst for positive change in character strengths. In keeping with this, we hypothesized that levels of self-reported character strengths would be higher in participants who completed the VIA-IS after each tragedy, compared to participants who completed the VIA-IS before each tragedy.

\section{Method}

\section{Procedure and Participants}

Authentic Happiness. We recruited participants from the pool of individuals who visited the website Authentic Happiness (www.authentichappiness.org), which is affiliated with the University of Pennsylvania's Positive Psychology Center. Authentic Happiness is a useful platform for conducting psychological research, especially research that examines national or local responses to events, as it contains 19 different measures related to positive psychology. The 
Institutional Review Board at the University of Pennsylvania has approved the use of these data for research purposes. Dr. Peterson helped develop the assessment portal of this website as a way to advance both the science and dissemination of positive psychology. Participants who create an account have full access to all 19 measures and receive personalized feedback upon completion of any questionnaire. Account creation includes inputting several demographic measures including age, gender, education, employment, and zip code. For the present study, we restricted our analyses to participants who completed the VIA-IS (Peterson \& Seligman, 2004) within specified timeframes and geographic locations (as detailed below). We did not examine any other measures besides the VIA-IS.

Timeframe. To explore PTG following three recent shooting tragedies in the U.S., we restricted our sample to those who responded to the VIA-IS in either the eight months preceding one of the events or the two months following. We selected eight months because this timeframe provided a reasonably large sample and would produce a baseline that would likely be resistant to any other significant events during the time period. The Virginia Tech shooting occurred on April 16, 2007, the theater shootings in Aurora, Colorado occurred on July 20, 2012 and the Sandy Hook school shooting in Newtown, Connecticut occurred on December 14, 2012. Thus, participants included those who completed the VIA questionnaire between August 15, 2006 to June 15, $2007(n=97,693)$, November 19, 2011 to September 19, $2012(n=223,857)$, and April 13, 2012 to February 13, $2013(n=223,935)$. Following the example of Peterson and Seligman (2003), we excluded people who completed the questionnaires on the days that the tragedies occurred. During these time periods, a total of 545,485 respondents completed the VIA-IS.

Geographic location. Although these events gained national and international media coverage, we believed that the individuals most affected (and most likely to report different 
levels of strengths following the event) would be those most closely connected with the specific communities where the shootings occurred. Thus, we restricted comparisons to participants living within a 100-mile radius of where tragedy occurred based on the zip code information $(n=$ 31,429). We selected 100-miles rather than merely using state of residence because it indicated that participants would be living close to the tragedies, thus increasing the possibility that respondents personally identify with each community and/or may know individuals within each community.

Demographics. Participants were $60.7 \%$ female. Participants were highly educated with $81.8 \%$ reporting attending at least some college and $22.2 \%$ completing some form of graduatelevel education. Age was collected using a categorical variable with nine intervals (13-15, 16-17, 18-20, 21-24, 25-34, 35-44, 45-54, 55-64, and 65+). To estimate average age, the midpoint of each interval was used (e.g., 29.5 for the 25-34 interval). For the $65+$ group, because it is not an interval, we used 69.5 years as the estimate as this was consistent with the values for the previous four intervals. Using this estimate, the approximate average age of the sample was 31.52 years, $S D=12.85$. Demographic variables (gender, age, and education) did not differ across the samples for each time periods stratified by the events.

\section{Measures}

The VIA-IS is a 240-item measure that contains 10 items for each of 24 character strengths (e.g., leadership, creativity, honesty, kindness, etc.). Each item is a strength-relevant statement (e.g., "In a group, I try to make sure everyone feels included") and participants respond on a scale from 1 (very much unlike me) to 5 (very much like me). In the current dataset, we only had access to each participant's mean value for each strength. Because we did not have access to responses for each item, we could not conduct psychometric evaluation of the 
scale. However, in previous samples the VIA-IS has demonstrated high levels of internal consistency within each strength subscale $(\alpha \mathrm{s}>.70)$ and high test-retest reliability (Peterson, Park, \& Seligman, 2005; Peterson \& Seligman, 2004).

\section{Results}

\section{Main Analyses: Overall Differences Across Time}

We computed one-way multivariate analyses of variance (MANOVA) with time period (eight months prior, one month post, two months post) as the three-level between-subjects factors and the 24 scale scores as the dependent variables. A separate MANOVA was calculated for each event leading to three MANOVA tests. The overall $F$ test was significant for Sandy Hook, $F(48,51,406)=3.62, p<.001$, but not for Virginia Tech, $F(48,3,824)=1.16, p=.21$ and Aurora, Colorado, $F(48,7,476)=1.25, p=.11$. This suggests differences in the mean levels of strengths reported by those completing the VIA-IS in the immediate aftermath of the Sandy Hook event but not for the Virginia Tech and Aurora, Colorado events. In order to first understand the overall pattern of differences in strengths, we constructed a histogram of the effect sizes $(d \text { and } A)^{l}$ for means differences and probability of superiority between the pre-event group and post-event group at both the 1- and 2-month interval. Figures 1 and 2 display these effect sizes for each of the groups. From the plot in Figure 1, we can observe that mean levels of strengths were predominantly lower for individuals near Sandy Hook in the time period one month after the event but higher in the period two months after the event. For Virginia Tech, an opposite pattern emerges, with predominantly higher means one month after the event and lower

\footnotetext{
${ }^{1}$ The superiority statistic $(A)$ estimates the probably that a member of one population would score higher than a member of another population on the given characteristic (Grissom \& Kim, 2005). In this case, it represents the estimate of the probability that a person's results of a given strength on the VIA-IS prior to the event would be higher than a person's results on the same strength in either the time period one month or two months after the event.
} 
means two months after the event. Lastly, for Aurora, Colorado, the effect sizes for mean differences $(d)$ are nearly normally distributed around zero, which one might expect if no differences in strengths were present. Figure 2 shows a mostly consistent pattern, with higher superiority statistics during the period one month after the event for Virginia Tech, the period two months after the event for Sandy Hook, and a symmetric distribution for both time periods for Aurora, Colorado that is centered close to $50 \%$. Thus, it appears that the main hypothesis, of differences in strengths following the events, is not supported.

\section{Exploratory Analyses: Individual Strengths Across Time}

We then examined differences on a scale-by-scale basis by computing $t$-tests comparing scores from the eight months preceding each event with the scores in the first and second month following each event (see Table 1). We chose to report these values for each event, even though the overall MANOVA was not significant for Virginia Tech or Aurora, Colorado because we believe researchers would be interested in the mean values for strengths across the time periods even with non-significant findings with regards to differences using the omnibus test. Given the size of our sample, these values are likely to be robust and thus we emphasize providing a clear picture of the data, rather than relying on the significance values. Table 1 also displays a large number of $t$-tests, however, we opted not to perform Bonferroni corrections and instead report exact effect sizes and significance values. Although Bonferroni corrections would adjust for number of tests, they would not adjust for size of sample. Thus, we encourage the use the mean values and effect sizes reported to guide subsequent research, especially in studies examining samples of different sizes. Table 1 includes all mean scores and standard deviations for each strength and each sample. 
For Virginia Tech, we observed higher levels of spirituality at one month. At two months, however, we observed reduced levels of bravery, honesty, modesty, prudence, and self-control compared to the eight months prior. For Aurora, Colorado, we observed significantly higher levels of prudence at one month. No strengths were significantly higher at two months than the pre-event period. Lastly, in the case of Sandy Hook, several strengths were significantly lower onemonth after the event including bravery, gratitude, honesty, hope, humor, kindness, leadership, love, modesty, perseverance, perspective, prudence, self-control, social intelligence, spirituality, teamwork, and zest. In contrast, love of learning was significantly greater one month after the event. Within the two-month post-event time period, however, several strengths were reported at higher levels than before, including fairness, gratitude, honesty, hope, kindness, leadership, love, modesty, and perseverance. Love of learning was actually reported at a lower level during this time period. It is worth noting that the magnitude of these changes, even the significant ones, are quite small (ranging from $d=-.13$ to $d=.15$ ).

\section{Discussion}

People often report that positive psychological changes emerge from the struggle with adversity and loss. Peterson and Seligman's (2003) past research suggested that these changes can be manifested as differences in character strengths, and that the strengths people endorse might differ after witnessing a national tragedy (not only when experiencing individual tragedies). The present study aimed to replicate and extend those findings by exploring whether higher levels of character strengths were reported following other more recent tragedies: the large-scale gun violence that occurred at Virginia Tech, Sandy Hook elementary school in Newtown, Connecticut, and an Aurora, Colorado movie theater. Results of the present study indicated that individuals in our sample (who all lived within 100 miles of where the shootings 
took place) reported statistically significant differences in character strengths one to two months after the Sandy Hook shooting, but not after the Virginia Tech and Aurora, Colorado events. Overall, the differences in character strengths were very small, and inconsistent across the tragedies: There were mostly lower values for Sandy Hook one month after the event, but higher values two months after the event, a reverse pattern for Virginia Tech, and no observable pattern for Aurora, Colorado.

Although differences in character strengths across different time points were small (with significant effect sizes ranging from -.13 to .15), it is important to remember that these represent the average levels of strengths reported within a subset of a population rather than changes at an individual level. Small shifts in a population on positive traits might still have an important impact (see Huppert, 2009). For example, the strengths associated with the virtue of temperance (such as self-control and prudence, which are conceptually related to the Big Five trait of conscientiousness) have been associated with multiple positive outcomes, including longevity, improved health, occupational attainment, marital stability, reduced drug use, and job performance (Roberts, Jackson, Fayard, Edmonds, \& Meints, 2009). Given the importance of such outcomes, even a small shift in strengths at the population level can have a significant societal impact. Thus, we posit that the size of differences in character strengths is not as problematic as is the lack of consistency of differences in strengths across the different samples (in terms of both time periods and geographic areas corresponding to tragedies).

Why were there so few meaningful and consistent differences in self-reported character strengths after these tragedies, particularly in light of Peterson and Seligman's (2003) aforementioned findings? We consider three possible interpretations. First, it may be that in spite of the great suffering and loss caused by the shootings, these local tragedies did not have a direct 
enough emotional impact on many individuals in our sample in order to serve as catalysts for change. According to Janoff-Bulman (1989), traumatic events can lead people to question their basic assumptions about the world. Growth emerges when the event is powerful enough to shatter an individual's assumptions, or core beliefs, about the world and prompts the individual to subsequent reflection (Tedeschi \& Calhoun, 2004). There is no doubt that the events studied here were powerful enough to shatter the core beliefs of individuals directly and personally exposed or affected, and we acknowledge that these shootings may have resonated with the many families with school-age children, but it is possible that many other individuals were able to maintain their assumptions about themselves and the world by being only indirectly impacted by the events.

Related to this point, the shootings investigated here may not share all of the characteristics of the $9 / 11$ attacks. In the case of $9 / 11$, the nature of the attacks (i.e., the first foreign attack on U.S. soil in half a century) likely led many Americans to question basic assumptions about the safety and predictability of their environment. Thus, even individuals who were only indirectly exposed or affected by the events of 9/11 might have felt directly and personally endangered by the attacks. Supporting this hypothesis, studies conducted after these attacks reported that many individuals only vicariously exposed to the attacks through the media experienced significant symptoms of stress and engaged in important meaning-making activities aimed at reducing the discrepancy between the meaning appraised from the event and preexisting global beliefs and goals (Park, 2010, p. 259-262; Schuster et al., 2001; Updegraff, Cohen Silver, \& Holman, 2008) such as coping (Folkman, 1997), making downward comparisons ("It could have been worse"; Taylor, Wood, \& Lichtman, 1983) and changing one’s goals in response to the event (Carver \& Scheier, 2000). While the impact of the shootings 
studied in this paper undoubtedly caused extreme suffering and had a profound impact on many people, it is possible that they were viewed differently from the 9/11 attacks, leading to responses different to those observed on $9 / 11$. We should note here the possibility that people were exposed to the 9/11 attacks repeatedly through the media in a manner different from how they were exposed to news of the shootings, which many have lead many to attach greater existential weight to the $9 / 11$ attacks. We were not able to examine this question here, because the Authentic Happiness dataset did not include measures of posttraumatic stress symptoms, coping efforts, and the like.

Additionally, it may also be the case that the 9/11 attacks provided individuals with an identifiable opponent (in this case, the terrorist group al-Qaeda) against which they could mobilize action. This could have led in turn to increased identification and possible deployment of specific character strengths. In contrast, the shootings may have been widely seen as random acts of violence with no clear target to respond against to prevent further attacks in the future.

A second interpretation of these findings is that character strengths may not change much after adversity. Considerable controversy exists surrounding whether people's retrospective assessment of PTG actually corresponds to measurable changes (Frazier et al., 2009; Taylor, 1983). The failure to find measurable differences in character strengths after community violence would be consistent with the claim that retrospective reports of PTG may constitute a form of coping through positive illusions. This interpretation, however, does not explain why Peterson and Seligman (2003) were able to detect such changes after the attacks of 9/11. More research using diverse samples (including individuals directly exposed to trauma, as opposed to vicariously or indirectly affected by trauma) and multiple assessment methods are needed in order to test this interpretation. 
A third interpretation is that our findings may have resulted from methodological features of the study. It may be that the time frame used here was not sensitive enough to allow us to detect effects: Changes in character strengths may emerge quicker or slower than the one- and two-month time frames used in the present analyses. In addition, it is possible that participants may have based their responses on the VIA-IS on more stable perceptions of their character, rather than carefully considering their behaviors in the specific, short time frame that is intended. Indeed, character strengths are typically discussed as rather stable trait-like differences, in which case we may not expect them to change greatly over short periods. Lastly, and perhaps most importantly, we did not follow people over time but rather looked at differences from other respondents to the VIA-IS. It could be that those who visited the website during this time period were not the ones most likely to exhibit change and thus results reflect general patterns of the most commonly-endorsed strengths that are observed when comparing mean values within US samples (e.g., Park et al., 2006).

The present study's limitations constrain the conclusions that can be drawn. First, because the analyses were based on archival data, we were limited only to the measures included on the website. For example, the website included no direct measure of PTG, such as the Posttraumatic Growth Inventory (Tedeschi \& Calhoun, 1996) and lacked demographic variables (e.g., race/ethnicity) that would provide a more thorough understanding of the characteristics of the respondents. Second, people may or may not return to this website and complete the measure again. Thus, our results reflect group-level patterns of response rather than individual change. However, if the tragedies had widespread and particularly strong influences on character strength levels, then one might expect to observe higher sample means after the tragedy than before (despite the limitations of our method). Lastly, our sample included a self-selected and possibly 
unique sample: Authentic Happiness website visitors are people who are interested in, and intentionally seek out, information about positive psychology, human flourishing, and character. Furthermore, the sample was comprised of highly educated and mostly female respondents and was a relatively young sample with the modal respondent between the ages of 25-34. Their reports of character strengths, as well as the patterns of stability and change of their strengths following important events, may not generalize to broader populations. It is also possible that the shootings may have affected individuals who subsequently decided to visit the website and complete the questionnaires, although this limitation would have also affected Peterson \& Seligman's (2003) data.

These limitations should be addressed in future studies. Most importantly, longitudinal designs need to follow people who have been emotionally impacted by trauma first-hand (e.g. Davis, Nolen-Hoeksema \& Larson, 1998; Frazier et al., 2009). Such prospective studies should measure not only character strengths but also psychopathology (i.e., posttraumatic stress symptoms, depression, or general distress), PTG, and other important domains of functioning (e.g., relationship satisfaction, meaning in life, and self-efficacy). Moreover, the psychological changes people experience in the wake of trauma and adversity can be both negative and positive, and measuring both trajectories of change simultaneously is an important goal for the future of PTG research (Tomich \& Helgeson, 2004). Frazier, Conlon, and Glaser (2001) found that female rape survivors who declined in self-reported PTG over time had similar self-reported levels of psychological distress as women who had never reported any PTG. These findings demonstrate how studies that rely solely on sample averages may mask important individual variability in trajectories of PTG. Ideally, future longitudinal studies would also include observers' reports to corroborate participants' own reports of growth. 


\section{Conclusion}

It is not uncommon for many individuals to feel uncomfortable discussing the positive effects of loss - as if, by investigating how adversity can lead to personal growth, adversity is justified or glorified. Given the horrific nature of the events investigated in the present study and the immense suffering inflicted on victims, their families, and their communities, it is very important for us to state here that no amount of psychological growth can ever make up for such tragedy. However, given that tragedies unfortunately do occur in spite of efforts to prevent them, we believe that psychological investigations of posttraumatic growth are important in order to help individuals live the best lives they can live in spite of what they have experienced. Exploring how tragedy might benefit character is therefore an important research endeavor, and a meaningful way to honor and extend the legacy of Christopher Peterson. It is our hope that the positive psychology research community may become stronger and wiser as it copes with the tragic loss of this brilliant scholar, through renewed commitment to Chris' study of character and through following Chris' lead in his dedication to his students, peers, and community.

\section{References}

Carver, C. S., \& Scheier, M. F. (2000). Scaling back goals and recalibration of the affect system are processes in normal adaptive self- regulation: Understanding "response shift" phenomena. Social Science \& Medicine, 50, 1715-1722.

Davis, C. G., Nolen-Hoeksema, S. \& Larson, J. (1998). Making sense of loss and benefiting from the experience: Two construals of meaning. Journal of Personality and Social Psychology, 75, 561-574.

Folkman, S. (1997). Positive psychological states and coping with severe stress. Social Science \& Medicine, 45, 1207-1221. 
Frazier, P., \& Kaler, M. (2006). Assessing the validity of self-reported stress-related growth. Journal of Consulting and Clinical Psychology, 74, 859-869.

Frazier, P., Tennen, H., Gavian, M., Park, C., Tomich, P., \& Tashiro, T. (2009). Does selfreported posttraumatic growth reflect genuine positive change? Psychological Science, 20, 912-919.

Frazier, P., Conlon, A., \& Glaser, T. (2001). Positive and negative life changes following sexual assault. Journal of Consulting and Clinical Psychology, 69, 1048-1055.

Grissom, R. J., \& Kim, J. J. (2005). Effect sizes for research: A broad practical approach. Mahwah, NJ: Erlbaum.

Helgeson, V. S., Reynolds, K. A., \& Tomich, P. L. (2006). A meta-analytic review of benefit finding and growth. Journal of Consulting and Clinical Psychology, 74, 797-816.

Hobfoll, S. E., Hall, B. J., Canetti-Nisim, D., Galea, S., Johnson, R. J., \& Palimieri, P. (2007). Refining our understanding of traumatic growth in the face of terrorism: Moving from cognitions to doing what is meaningful. Applied Psychology: An International Review, $56,345-366$.

Huppert, F. A. (2009). A new approach to reducing disorder and improving wellbeing. Perspectives on Psychological Science, 4, 108-111.

Janoff-Bulman, R. (1989). Assumptive worlds and the stress of traumatic events: Applications of the schema construct. Social Cognition, 7, 113-136.

Janoff-Bulman, R. (1992). Shattered assumptions. New York: Free Press.

Janoff-Bulman, R. (2004). Posttraumatic growth: Three explanatory models. Psychological Inquiry, 15, 30-34. 
Joseph, S., \& Linley, P. A. (2005). Positive adjustment to threatening events: An organismic valuing theory of growth through adversity. Review of General Psychology, 9, 262-280.

Joseph, S., \& Linley, P. A. (2008). Trauma, recovery, and growth: Positive psychological perspectives on posttraumatic stress. Hoboken, NJ: John Wiley \& Sons.

Joseph, S., Murphy, D., \& Regel, S. (2012). An affective-cognitive processing model of posttraumatic growth. Clinical Psychology \& Psychotherapy, 19, 316-325.

Lindstrom, C. M., Cann, A., Calhoun, L. G., \& Tedeschi, R. G. (in press). The relationship of core belief challenge, rumination, disclosure, and sociocultural elements to posttraumatic growth. Psychological Trauma: Theory, Research, Practice and Policy.

Linley, P. A., \& Joseph, S. (2004). Positive change following trauma and adversity: A review. Journal of Traumatic Stress, 17, 11-21.

Park, C. L. (2010). Making sense of the meaning literature: An integrative review of meaning making and its effects on adjustment to stressful life events. Psychological Bulletin, 136, 257-301.

Park, C. L., Aldwin, C. M., Fenster, J. R., \& Snyder, L. B. (2008). Pathways to posttraumatic growth versus posttraumatic stress: Coping and emotional reactions following the September 11, 2001, terrorist attacks. American Journal of Orthopsychiatry, 78, 300-312.

Park, N., Peterson, C., \& Seligman, M. E. P. (2006). Character strengths in fifty-four nations and the fifty US states. Journal of Positive Psychology, 1, 118-129.

Peterson, C. (2006). A primer in positive psychology. New York: Oxford University Press.

Peterson, C., Park, N., Pole, N., D'Andrea, W., \& Seligman, M. E. P. (2008). Strengths of character and posttraumatic growth. Journal of Traumatic Stress, 21, 214-217. 
Peterson, C., Park, N., \& Seligman, M. E. P. (2005). Assessment of character strengths. In G. P. Koocher, J. C. Norcross, \& S. S. Hill III (Eds.), Psychologists' desk reference (2 ${ }^{\text {nd }}$ ed., pp. 93-98). New York: Oxford University Press.

Peterson, C., \& Seligman, M. E. P. (2003). Character strengths before and after September 11. Psychological Science, 14, 381-384.

Peterson, C., \& Seligman, M. E. P. (2004). Character strengths and virtues: A handbook and classification. New York: Oxford University Press.

Prati, G., \& Pietrantoni, L. (2009). Optimism, social support, and coping strategies as factors contributing to posttraumatic growth: A meta-analysis. Journal of Loss and Trauma, 14, 364-388.

Roberts, B. W., Jackson, J. J., Fayard, J. V., Edmonds, G., \& Meints, J. (2009). Conscientiousness. In M. Leary \& R. Hoyle (Eds.), Handbook of Individual Differences in Social Behavior (pp. 369-381). New York, NY: Guilford.

Schuster, M. A., Stein, B. D., Jaycox, L. H., Collins, R. L., Marshall, G. N., Elliott, M. N., ... \& Berry, S. H. (2001). A national survey of stress reactions after the September 11, 2001, terrorist attacks. New England Journal of Medicine, 345, 1507-1512.

Schwarzer, R., \& Knoll, N. (2003). Positive coping: Mastering demands and searching for meaning. In S. J. Lopez \& C. R. Snyder (Eds.), Positive psychological assessment: A handbook of models and measures (pp. 393-409). Washington, DC: American Psychological Association.

Taku, K., Calhoun, L. G., Cann, A., \& Tedeschi, R. G. (2008). The role of rumination in the coexistence of distress and posttraumatic growth among bereaved Japanese university students. Death Studies, 32, 428-444. 
Taylor, S. E. (1983). Adjustment to threatening events: A theory of cognitive adaptation. American Psychologist, 38, 1161-1173. Taylor, S. E., Wood, J. V., \& Lichtman, R. R. (1983). It could be worse: Selective evaluation as a response to victimization. Journal of Social Issues, 39, 19-40.

Tedeschi, R. G., \& Calhoun, L. G. (1996). The Posttraumatic Growth Inventory: Measuring the positive legacy of trauma. Journal of Traumatic Stress, 9, 455-471.

Tedeschi, R. G., \& Calhoun, L. G. (2004). Posttraumatic growth: Conceptual foundations and empirical evidence. Psychological Inquiry, 15, 1-18.

Tomich, P. L., \& Helgeson, V. S. (2004). Is finding something good in the bad always good? Benefit finding among women with breast cancer. Health Psychology, 23, 16-23.

Updegraff, J. A., Silver, R. C., \& Holman, E. A. (2008). Searching for and finding meaning in collective trauma: Results from a national longitudinal study of the $9 / 11$ terrorist attacks. Journal of Personality and Social Psychology, 95, 709-722.

Zoellner, T., \& Maercker, A. (2006). Posttraumatic growth in clinical psychology—A critical review and introduction of a two component model. Clinical Psychology Review, 26, 626-653. 
Table 1

Mean Scores, Standard Deviations, and Effect Size Statistics (Cohen's d, Superiority Statistic A) for the Values in Action Inventory of Strengths (VIA-IS)

\begin{tabular}{|c|c|c|c|c|c|c|c|c|c|c|c|}
\hline Trait & $\begin{array}{l}\text { Mean pre VT } \\
(n=1,640)\end{array}$ & $\begin{array}{l}\text { Mean } 1 \text { month } \\
\text { after VT } \\
(n=184)\end{array}$ & $d$ & $A$ & $\begin{array}{c}\text { Mean } 2 \\
\text { months after } \\
\text { VT } \\
(n=113) \\
\end{array}$ & $\mathrm{d}$ & $A$ & $\begin{array}{l}\text { Mean pre CO } \\
(n=2,941)\end{array}$ & $\begin{array}{l}\text { Mean } 1 \text { month } \\
\text { after CO } \\
(n=431)\end{array}$ & $\mathrm{d}$ & $A$ \\
\hline \multicolumn{12}{|l|}{ Appreciation } \\
\hline Bravery & $3.71(0.62)$ & $3.77(0.58)$ & 0.06 & 52.75 & $3.55 *(0.55)$ & -0.13 & 41.35 & $3.78(0.61)$ & $3.76(0.66)$ & -0.02 & 49.40 \\
\hline Creativity & $3.79(0.68)$ & $3.78(0.71)$ & -0.01 & 50.11 & $3.79(0.68)$ & 0.00 & 49.67 & $3.77(0.69)$ & $3.74(0.67)$ & -0.02 & 48.77 \\
\hline Curiosity & $4.01(0.56)$ & $4.02(0.53)$ & 0.01 & 50.31 & $4.01(0.63)$ & 0.00 & 50.81 & $4.02(0.55)$ & $4.01(0.59)$ & -0.01 & 49.85 \\
\hline Fairness & $4.08(0.52)$ & $4.09(0.50)$ & -0.01 & 49.22 & $4.04(0.46)$ & -0.05 & 46.04 & $4.08(0.50)$ & $4.10(0.51)$ & 0.03 & 51.83 \\
\hline Forgiveness & $3.71(0.67)$ & $3.76(0.65)$ & 0.05 & 52.20 & $3.72(0.69)$ & 0.01 & 50.30 & $3.72(0.66)$ & $3.72(0.67)$ & 0.00 & 49.78 \\
\hline Gratitude & $3.93(0.62)$ & $4.01(0.53)$ & 0.07 & 52.60 & $3.84(0.70)$ & -0.08 & 46.79 & $3.97(0.60)$ & $3.99(0.62)$ & 0.03 & 51.50 \\
\hline Honesty & $4.02(0.49)$ & $4.06(0.49)$ & 0.05 & 52.03 & $3.92 *(0.50)$ & -0.10 & 43.83 & $4.08(0.50)$ & $4.07(0.50)$ & -0.02 & 49.32 \\
\hline Hope & $3.68(0.69)$ & $3.76(0.61)$ & 0.07 & 52.92 & $3.60(0.75)$ & -0.06 & 47.16 & $3.82(0.67)$ & $3.83(0.66)$ & 0.00 & 50.08 \\
\hline Humor & $3.88(0.65)$ & $3.81(0.66)$ & -0.06 & 47.12 & $3.82(0.64)$ & 0.04 & 46.62 & $3.93(0.63)$ & $3.90(0.64)$ & -0.03 & 48.30 \\
\hline Judgment & $4.04(0.51)$ & $4.07(0.47)$ & 0.04 & 50.87 & $3.98(0.54)$ & -0.06 & 45.80 & $4.02(0.52)$ & $4.06(0.52)$ & 0.06 & 52.89 \\
\hline Kindness & $4.03(0.55)$ & $4.04(0.49)$ & 0.01 & 49.70 & $3.95(0.55)$ & -0.07 & 45.26 & $4.01(0.55)$ & $4.02(0.54)$ & 0.01 & 50.49 \\
\hline Leadership & $3.83(0.56)$ & $3.84(0.51)$ & 0.01 & 49.86 & $3.78(0.47)$ & -0.04 & 46.78 & $3.86(0.55)$ & $3.88(0.58)$ & 0.02 & 51.20 \\
\hline Love & $3.96(0.59)$ & $3.97(0.59)$ & 0.01 & 50.86 & $3.93(0.58)$ & -0.03 & 47.61 & $3.97(0.60)$ & $3.96(0.59)$ & -0.01 & 49.24 \\
\hline \multicolumn{12}{|l|}{ Love of } \\
\hline Learning & $3.85(0.66)$ & $3.85(0.62)$ & 0.00 & 49.82 & $3.88(0.67)$ & 0.02 & 51.47 & $3.76(0.66)$ & $3.80(0.67)$ & 0.04 & 51.74 \\
\hline Modesty & $3.47(0.64)$ & $3.54(0.69)$ & 0.06 & 52.83 & $3.34 *(0.71)$ & -0.10 & 44.48 & $3.52(0.63)$ & $3.57(0.62)$ & -0.05 & 52.09 \\
\hline Perseverance & $3.70(0.68)$ & $3.71(0.67)$ & 0.01 & 50.25 & $3.58(0.72)$ & -0.09 & 45.42 & $3.82(0.66)$ & $3.84(0.64)$ & 0.02 & 50.78 \\
\hline Perspective & $3.81(0.54)$ & $3.87(0.51)$ & 0.06 & 53.14 & $3.73(0.59)$ & -0.08 & 45.30 & $3.87(0.55)$ & $3.89(0.55)$ & 0.02 & 50.11 \\
\hline Prudence & $3.54(0.60)$ & $3.56(0.61)$ & 0.02 & 51.88 & $3.42 *(0.61)$ & -0.10 & 44.82 & $3.55(0.60)$ & $3.62 *(0.61)$ & 0.08 & 53.88 \\
\hline Self-control & $3.35(0.64)$ & $3.29(0.58)$ & -0.05 & 46.67 & $3.20 *(0.64)$ & -0.11 & 43.40 & $3.52(0.64)$ & $3.53(0.62)$ & 0.00 & 49.76 \\
\hline \multicolumn{12}{|l|}{ Social } \\
\hline intelligence & $3.81(0.56)$ & $3.88(0.54)$ & 0.07 & 53.90 & $3.71(0.59)$ & -0.08 & 44.79 & $3.86(0.56)$ & $3.82(0.59)$ & -0.06 & 46.97 \\
\hline Spirituality & $3.49(0.91)$ & $3.72 * *(0.88)$ & 0.15 & 50.34 & $3.37(0.96)$ & -0.06 & 46.51 & $3.46(0.94)$ & $3.53(0.93)$ & 0.05 & 51.97 \\
\hline Teamwork & $3.77(0.57)$ & $3.79(0.53)$ & 0.02 & 51.20 & $3.70(0.58)$ & -0.06 & 46.06 & $3.87(0.56)$ & $3.85(0.56)$ & -0.02 & 48.57 \\
\hline Zest & $3.62(0.67)$ & $3.63(0.62)$ & 0.01 & 50.38 & $3.56(0.72)$ & -0.04 & 48.06 & $3.72(0.65)$ & $3.68(0.63)$ & -0.04 & 47.41 \\
\hline
\end{tabular}

Note: Standard deviations are in parentheses. VT $=$ Virginia Tech, $\mathrm{CO}=$ Aurora, Colorado Theater Shooting, $\mathrm{SH}=\mathrm{Sandy}$ Hook

School Shooting. $* p<.05, * * p<.01$. 


\begin{tabular}{|c|c|c|c|c|c|c|c|c|c|c|}
\hline Trait & $\begin{array}{l}\text { Mean } 2 \\
\text { months } \\
\text { after CO } \\
(n=391)\end{array}$ & $d$ & $A$ & $\begin{array}{c}\text { Mean pre } \\
\text { SH } \\
(n=21,994)\end{array}$ & $\begin{array}{c}\text { Mean } 1 \\
\text { month after } \\
\text { SH } \\
(n=1,232) \\
\end{array}$ & $d$ & $A$ & $\begin{array}{c}\text { Mean } 2 \\
\text { month after } \\
\text { SH } \\
(n=2,503) \\
\end{array}$ & $d$ & $A$ \\
\hline $\begin{array}{l}\text { Appreciation } \\
\text { of beauty }\end{array}$ & $3.71(0.70)$ & 0.05 & 52.14 & $3.76(0.70)$ & $3.76(0.71)$ & 0.00 & 50.05 & $3.77(0.71)$ & 0.01 & 50.65 \\
\hline Bravery & $3.77(0.60)$ & 0.00 & 49.47 & $3.75(0.62)$ & $3.72 *(0.62)$ & -0.03 & 48.31 & $3.77(0.63)$ & 0.02 & 50.76 \\
\hline Creativity & $3.76(0.69)$ & -0.01 & 49.39 & $3.82(0.66)$ & $3.79(0.68)$ & -0.02 & 48.69 & $3.81(0.69)$ & -0.01 & 49.77 \\
\hline Curiosity & $3.97(0.57)$ & -0.05 & 47.94 & $3.99(0.55)$ & $3.96(0.58)$ & -0.02 & 49.33 & $3.97(0.56)$ & -0.01 & 49.42 \\
\hline Fairness & $4.10(0.54)$ & 0.03 & 51.48 & $4.07(0.54)$ & $4.05(0.54)$ & -0.02 & 48.65 & $4.11 * *(0.55)$ & 0.04 & 52.19 \\
\hline Forgiveness & $3.72(0.66)$ & 0.00 & 49.87 & $3.68(0.69)$ & $3.67(0.70)$ & -0.01 & 49.72 & $3.70(0.70)$ & 0.02 & 50.79 \\
\hline Gratitude & $3.96(0.62)$ & -0.01 & 50.07 & $3.99(0.60)$ & $3.95 *(0.62)$ & -0.03 & 48.27 & $4.05 * *(0.59)$ & 0.06 & 52.78 \\
\hline Honesty & $4.09(0.47)$ & 0.02 & 50.28 & $4.07(0.50)$ & $4.02 * *(0.53)$ & -0.04 & 47.57 & $4.10 * *(0.52)$ & 0.04 & 52.59 \\
\hline Hope & $3.78(0.68)$ & -0.04 & 46.41 & $3.86(0.68)$ & $3.78 * *(0.70)$ & -0.05 & 46.68 & $3.89 *(0.68)$ & 0.03 & 51.48 \\
\hline Humor & $3.94(0.64)$ & 0.01 & 50.43 & $3.92(0.64)$ & $3.83 * *(0.66)$ & -0.06 & 46.17 & $3.93(0.65)$ & 0.01 & 50.79 \\
\hline Judgment & $4.02(0.51)$ & 0.00 & 49.29 & $4.04(0.53)$ & $4.02(0.54)$ & 0.02 & 48.79 & $4.04(0.55)$ & 0.00 & 50.12 \\
\hline Kindness & $4.04(0.56)$ & 0.03 & 51.85 & $4.04(0.56)$ & $3.98 * *(0.57)$ & -0.05 & 46.82 & $4.09 * *(0.55)$ & 0.05 & 52.36 \\
\hline Leadership & $3.85(0.57)$ & -0.01 & 49.62 & $3.89(0.58)$ & $3.83 *(0.57)$ & -0.04 & 47.08 & $3.94 * *(0.58)$ & 0.05 & 52.39 \\
\hline Love & $4.02(0.56)$ & 0.06 & 52.41 & $3.99(0.59)$ & $3.93 * *(0.62)$ & -0.04 & 47.38 & $4.03 * *(0.58)$ & 0.04 & 52.15 \\
\hline \multicolumn{11}{|l|}{ Love of } \\
\hline Learning & $3.74(0.64)$ & -0.02 & 49.18 & $3.76(0.67)$ & $3.80 *(0.66)$ & 0.03 & 51.67 & $3.69 * *(0.68)$ & -0.06 & 47.02 \\
\hline Modesty & $3.53(0.62)$ & 0.01 & 50.03 & $3.54(0.64)$ & $3.49 *(0.64)$ & -0.03 & 47.92 & $3.58 * *(0.64)$ & 0.04 & 52.15 \\
\hline Perseverance & $3.80(0.65)$ & -0.01 & 49.13 & $3.82(0.69)$ & $3.72 * *(0.73)$ & -0.07 & 45.97 & $3.85 *(0.70)$ & 0.03 & 51.63 \\
\hline Perspective & $3.86(0.55)$ & 0.00 & 49.15 & $3.86(0.56)$ & $3.80 *(0.59)$ & -0.04 & 47.53 & $3.87(0.58)$ & 0.01 & 50.49 \\
\hline Prudence & $3.54(0.68)$ & -0.02 & 48.73 & $3.64(0.62)$ & $3.60 *(0.61)$ & -0.03 & 47.8 & $3.66(0.64)$ & 0.02 & 51.24 \\
\hline Self-control & $3.51(0.63)$ & -0.02 & 49.06 & $3.51(0.63)$ & $3.45 *(0.66)$ & -0.04 & 47.57 & $3.50(0.64)$ & 0.00 & 49.70 \\
\hline Social & & & & & & & & & & \\
\hline intelligence & $3.86(0.55)$ & 0.00 & 49.38 & $3.87(0.56)$ & $3.79 * *(0.58)$ & -0.07 & 45.9 & $3.89(0.56)$ & 0.02 & 51.05 \\
\hline Spirituality & $3.41(0.89)$ & -0.04 & 48.03 & $3.50(0.89)$ & $3.43 *(0.87)$ & -0.04 & 47.41 & $3.55^{*}(0.88)$ & 0.03 & 51.48 \\
\hline Teamwork & $3.88(0.54)$ & 0.01 & 50.16 & $3.90(0.56)$ & $3.83 * *(0.59)$ & -0.05 & 46.69 & $3.95 * *(0.56)$ & 0.05 & 52.55 \\
\hline Zest & $3.67(0.66)$ & -0.05 & 47.82 & $3.71(0.64)$ & $3.63 * *(0.65)$ & -0.05 & 46.81 & $3.71(0.65)$ & 0.00 & 50.18 \\
\hline
\end{tabular}

Note: Standard deviations are in parentheses. VT = Virginia Tech, CO = Aurora, Colorado Theater Shooting, SH $=$ Sandy Hook School Shooting. ${ }^{*} p<.05,{ }^{*} p<.01$. 


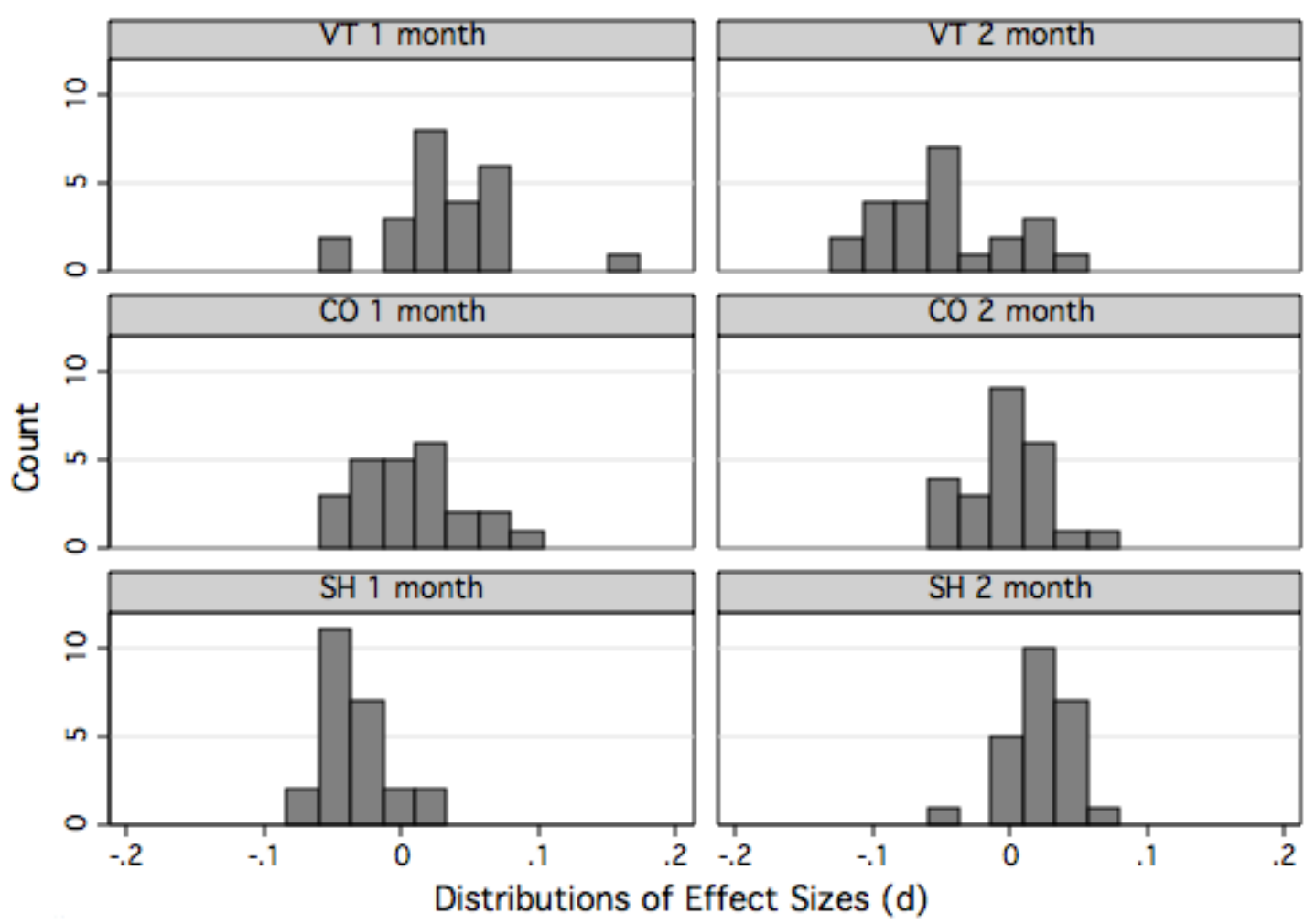

Figure 1. Distribution of effect sizes (d) of differences between pre and post groups for VIA strengths 


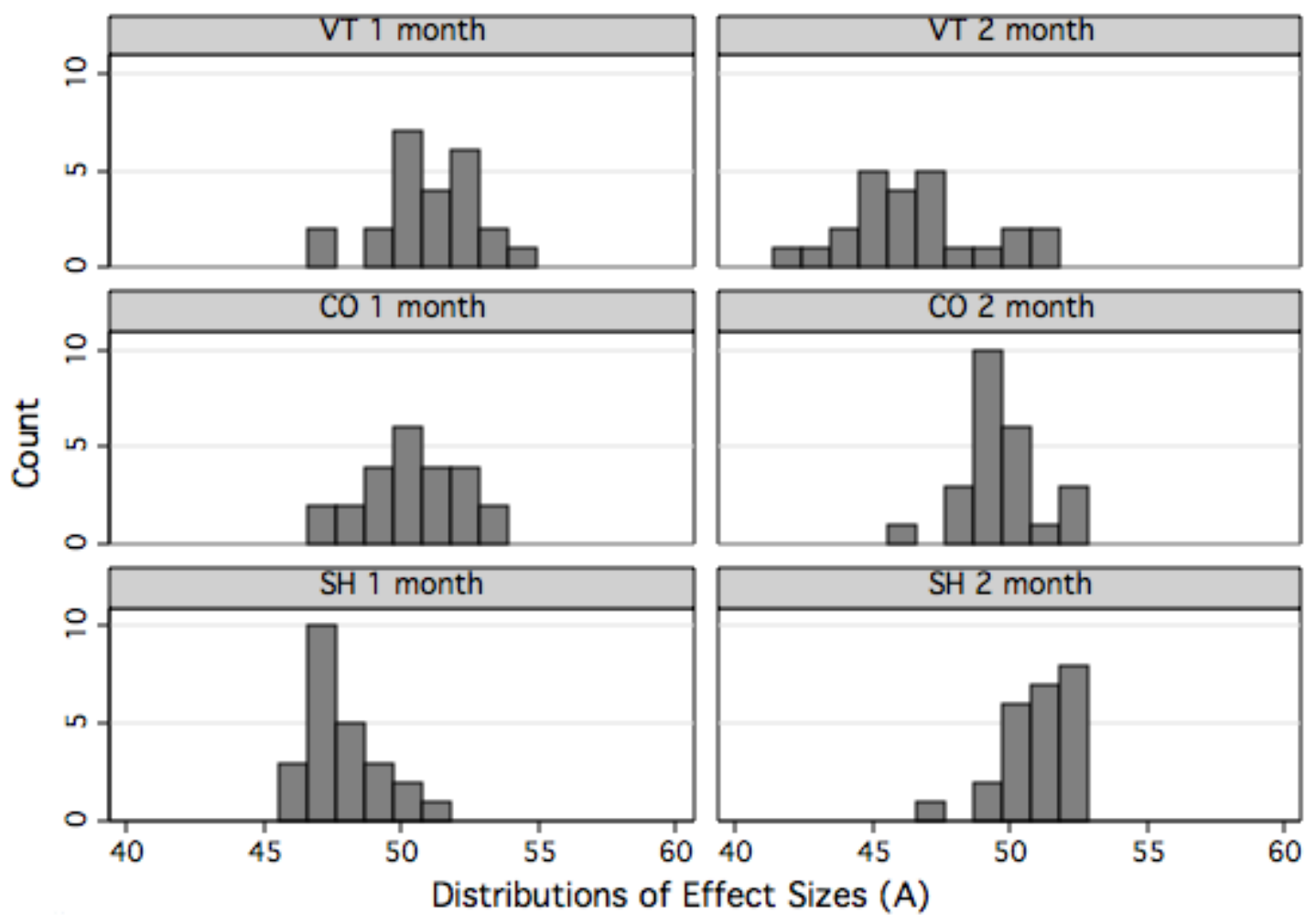

Figure 2. Distribution of effect sizes (A) of superiority statistics at pre and post groups for VIA strengths 